Asen O. Ivanov

Faculty of Information

University of Toronto

Toronto, Ontario

\title{
The Analytical Potential of Cultural Meanings: Insights from the Analysis of Evaluation Practices in a Digital News Archive \\ (Paper)
}

\begin{abstract}
:
By drawing on insights from a doctoral project, this paper makes a case for examining the cultural meanings of information practices. The analytical value of this approach is elucidated through examples from an analysis of the digital curation practices at a digital broadcasting archive. The paper concludes by suggesting what role this approach, and information practice research more broadly, could play in the critical scholarship on data curation and data science.
\end{abstract}

\section{Résumé:}

En s'appuyant sur les idées d'un projet de doctorat, cet article plaide pour l'examen des significations culturelles des pratiques de l'information. La valeur analytique de cette approche est illustrée par des exemples tirés d'une analyse des pratiques de conservation numérique dans des archives de radiodiffusion numérique. L'article conclut en suggérant le rôle que cette approche, et la recherche sur la pratique de l'information, pourrait jouer dans la recherche critique sur la conservation des données et la science des données. 


\section{Introduction}

This paper presents central ideas from a doctoral project on the digital curation practices at the television news archive of the Canadian Broadcasting Corporation (CBC). The project is based on the view that aside from being socio-technical systems (i.e., articulations of people, information, and technology), information practices are also supported by cultural systems (i.e., dynamic, typically fragmented, articulations of cultural meanings that give coherence and structure to social action) (Swidler 1986; DiMaggio 1997). The overarching goal of the project, thus, is to demonstrate that analytical attention to the cultural dimension of information practices could produce better causal explanations of the variance of information practices across social and organizational contexts (Courtright 2007). This paper discusses the backbone of this argument and fleshes it out by presenting selected project findings.

\section{Theoretical perspective}

The project is informed by the ontological and epistemological tenets of the field of practice theory. Most fundamentally, adopting a practice theory perspective requires privileging social practices as a conceptual unit of analysis, as opposed to either individual actions (a microanalytical perspective) or broader societal dynamics (a macro-analytical perspective). The mesoanalytical perspective of practice theory — which has been dubbed in various literatures as “methodological situationalism” (e.g., see, Knorr-Cetina 1981, 7-15; Hutter and Stark 2015, 35) - is not unfamiliar to information studies, and arguably, it alone accounts for the methodological rift between the information behaviour / information practice research orientations (cf. Savolainen 2007, 126). The tenets of practice theory have already been elaborated by other authors (e.g., Palmer and Cragin 2008; Cronin 2008, 471-472; Huizing and Cavanagh 2011) and are frequently applied in information studies research.

\section{Cultural meanings as a causal variable: Toward an expanded notion of context}

In line with current developments in practice theory (cf. Ivanov 2017; Welch and Warde 2017), I suggest that we should accord more attention to the analysis of cultural meanings in information 
practices. This argument is predicated on the view that we cannot engage with the world without attaching meaning to the actors and objects in our environments. That is not to suggest that our understanding of the world is always and necessary correct, but only that meaning is prerequisite for any form of social action. Examining the cultural meanings social actors attach to their immediate environment is thus a necessary component for developing causal explanations of both motivation and action. Put in other words, to understand why people act the way they do, we ought to understand the meanings behind their actions - a point that has already been absorbed in sociology and organizational studies (See, Dobbin 1994; 2009)

To assert, however, that the cultural meanings social actors attach to their environment is an important object of analysis in explaining both motivation and action is not to assume a social constructivist position thereby reducing the material world (and by extension information) to a meaningless object on which social constructions are projected (e.g., Hjørland 2007). Rather the goal is to examine how cultural meanings give coherence and direction to social actions, but in doing so, to remain attentive to the extent to which the range of meanings available to social actors in a given context are in turn constrained by objective conditions (Reed 2011, 123-162; for more on the latter point, see also Zuckerman 2012). The remainder of this paper offers a brief indication of the insights such analytical perspective can garner.

\section{Data and Methods}

The data collection for this project was focused on documenting the tools, interactions, and dynamics at the $\mathrm{CBC}$ news archive and the cultural meanings archivists attach to their actions and environment. Data was collected and analyzed in three iterative stages (Fig. 1) and was analyzed qualitatively again in iterative stages (Fig. 2). The analysis employed triangulation techniques (Denzin 1970) and in particular made use of the matrix data display techniques developed by Miles, Huberman, and Saldaña (2014, 105-255). The practices of all five departments at the $\mathrm{CBC}$ news archive (acquisition, cataloguing, media management, preservation, and visual resources) were analyzed in relation to various concepts and arguments in information studies and related literatures. The discussion that follows reflects on a small portion of this analysis, namely, on the evaluation practices at the acquisition department at the CBC news archive. 
Ivanov, Asen - CAIS 2018

\section{Evaluation at the CBC acquisition department}

Three main classes of news materials are acquired and preserved by the news archive. These are: (1) Full programs - literally full programs in their entirety acquired and preserved as they air on national TV. (2) Items - all elements (segments) that make up a news show, which are subdivided into several categories (e.g., live reports, reports from studio, interviews, etc.). And (3) stox (stock footage), which includes materials generated in the production of news that have not made it into a broadcast but are nonetheless preserved either for reuse or for their cultural and historical value. The acquisition department processes current materials, ingested in the system on daily basis, as well as legacy materials (archival video tapes going back to the 1960s), which are digitized on ongoing basis. The temporal constraints on the practices are high. News materials are held on the CBC's near-line servers only for one week before being deleted in the so-called weekly purge cycle. It is within this narrow timeframe that archivists must evaluate the material and decide on its acquisition.

Examining the evaluation practices at the acquisition department led to the conceptualization of four evaluation logics, which I have called-public record logic, heritage logic, corporate memory logic, and reuse logic. The four logics provide broad frameworks of cultural meanings that guide acquisition.

The criteria associated with the public record logic are provenance, context, and function. Strictly speaking, materials are acquired for the accountability they can provide to future audiences/archival users, and that is specifically the case with the acquisition of full programs, which are acquired as elements for building a reliable historical record of the CBC's news broadcasting operations. The evaluation criteria associated with the heritage logic are relevance to Canadian history and culture, and those associated with corporate memory logic are relevance to the $\mathrm{CBC}$ history and culture, which includes the corporation as a whole as well as the careers of notable CBC personalities. Both items and stox can be acquired in relation to those two logics. Lastly, the criteria associated with reuse logic are social relevance and newsworthiness of the story when the materials under evaluation are items; but when the materials under evaluation are stox, the criteria appear to be uniqueness, production cost, and aesthetic quality.

Furthermore, the data indicates that the complexity of evaluation practices changes relative to the nature of news materials under evaluation. Acquisition of full programs is almost automatic and not much deliberation is given on their potential value; it is presumed that they 
have value as public records. But the complexity of evaluation increases with items, and it is very high with stox. One way to account for this is to acknowledge that the evaluation of different classes of archival materials straddles between clear, objective evaluation principles and the grey area of subjectivity, requiring archivists to draw on their personal tastes and preferences to determine if materials are worth acquiring (Fig. 3). This is an example of a point alluded to earlier, namely, that the stable, objective properties of information (in this case, the classes of news materials) constrain the scope of cultural meanings social actors bring to their interaction with information (in this case the interaction being evaluation of news materials).

The analysis also revealed another objective factor that helps us explain the dynamics of evaluation practices, what I have designated as the institutional context at the CBC news archive. More specifically, my interviews with archivists and my analysis of organizational documents suggest that the dual-role of the $\mathrm{CBC}$ as both a public institution and a commercial broadcaster influences the nature of evaluation practices, which appear to be guided by two different goalson the one hand, a goal to serve the specific needs of the organization by acquiring materials that can be reused in news productions, and on the other hand, a strong commitment and responsibility to preserving Canadian cultural heritage. This places the archivists in a dual-role as both organizational stakeholders striving to maximize organizational resources and at the same time as custodians of cultural heritage.

Collectively, the analysis of the cultural meanings CBC news archivists bring to their evaluation practices and of the objective conditions constraining these meanings offer an alternative explanation of how archival acquisition works. Based on this analysis it becomes evident that each type of archival news materials can potentially yield multiple values (Fig. 4). What drives evaluation and acquisition then is not the values inherent in news materials - which is the explanation afforded by, for example, archival appraisal theory-but rather the cultural and organizational functions that the archive performs. This is one, albeit briefly articulated, example of the insights that the analysis of cultural meanings can contribute to the study of information practices in context. 


\section{Conclusion}

This paper presented an argument for the analytical significance of studying cultural meanings as means of developing causal explanations of information practices. The argument being that because we know that we interact with information meaningfully, we ought to study the meanings underpinning these interactions. This, I would propose, is a valid critical perspective that information practice research could contribute to the emerging fields of data curation and data science. With its established tradition of investigating human and contextual factors, information practice research is uniquely positioned to take on questions that can enrich our understanding of how the people who collect, curate, and use data actually think about what they do- thus, helping to fill a known gap in the critical scholarship on the topic (Andrejevic 2014; Metcalf and Crawford 2016). 
Ivanov, Asen - CAIS 2018

\section{REFERENCES}

Andrejevic, Mark. 2014. "Big data, big questions: The big data divide." International Journal of Communication 8: 1673-1689.

Courtright, Christina. 2007. "Context in information behavior research." Annual Review of Information Science and Technology 41: 273-306.

Cronin, Blaise. 2008. "The sociological turn in information science." Journal of Information Science 34 (4): 465-475.

Denzin, Norman. 1970. "Strategies of Multiple Triangulation." In The Research Act: A Theoretical Introduction to Sociological Method, 297-314. Chicago, IL: Aldine Publishing

DiMaggio, Paul J. 1997. “Culture and cognition.” Annual Review of Sociology 23 (1): 263-287.

Dobbin, Frank. 1994. "Cultural models of organization: The social construction of rational organizing principles.” In The Sociology of Culture: Emerging Theoretical Perspectives, edited by Diana Crane, 117-141. Oxford: Basil Blackwell.

—. 2009. "How Durkheim's theory of meaning-making influenced organizational sociology." In The Oxford Handbook of Sociology and Organization Studies, edited by Paul S. Adler, 200-222. Oxford, New York: Oxford University Press.

Hjørland, Birger. 2007. "Information: Objective or subjective/situational." Journal of the Association for Information Science and Technology 58 (10): 1448-1456.

Hutter, Michael and David Stark. 2015. "Pragmatist perspectives on valuation: An introduction." In Moments of Valuation: Exploring Site of Dissoance, edited by Ariane Berthoin Antal, Michael Hutter, and David Stark, 1-15, Oxford, UK: Oxford University Press.

Ivanov, Asen Ognyanov. "Practice theory: A new approach for archival and recordkeeping research." Records Management Journal 27 (2): 104-124.

Knorr-Cetina, Karin. 1981. "The micro-sociological challenge of macro-sociology: Towards a reconstruction of social theory and methodology" In Advances in Social Theory and Methodology: Toward an Integration of Micro- and Macro-Sociologies, edited by Karin Knorr-Cetina and Aaron Cicourel, 1-47, New York: Routledge.

Metcalf, Jacob, and Kate Crawford. 2016. "Where are human subjects in big data research? The emerging ethics divide." Big Data \& Society 3 (1): 1-14

Miles, Matthew B., A. Michael Huberman, and Johnny Saldaña. 2014. Qualitative Data Analysis (3rd ed.). Thousand Oaks, CA: Sage. 
Palmer, Carole L., and Melissa H. Cragin. 2008. "Scholarship and disciplinary practices." Annual Review of Information Science and Technology 42: 163-212.

Reed, Isaac Ariail. 2011. Interpretation and Social Knowledge: On the Use of Theory in the Human Sciences. Chicago, IL: University of Chicago Press

Savolainen, Reijo. 2007. "Information behavior and information practice: Reviewing the umbrella concepts of information-seeking studies." The Library Quarterly 77 (2): 109132.

Schatzki, Theodore R. 2001. "Introduction: Practice Theory.” In The Practice Turn in Contemporary Theory, edited by Theodore R. Schatzki, Karin Knorr-Cetina, and Eike von Savigny, 11-24. New York: Psychology Press.

Swidler, Ann. 1986. "Culture in action: Symbols and strategies." American Sociological Review 51 (2): 273-286.

Welch, Daniel and Alan Warde. 2017. "How should we understand 'general understandings'?" In The Nexus of Practices: Connections, Constellations, Practitioners, edited by Allison Hui, Theodore Schatzki and Elizabeth Shove, 183-197. New York: Routledge.

Zuckerman, W. Ezra. 2012. "Construction, concentration, and (dis) continuities in social valuations." Annual Review of Sociology 38: 223-245. 


\section{FIGURES}

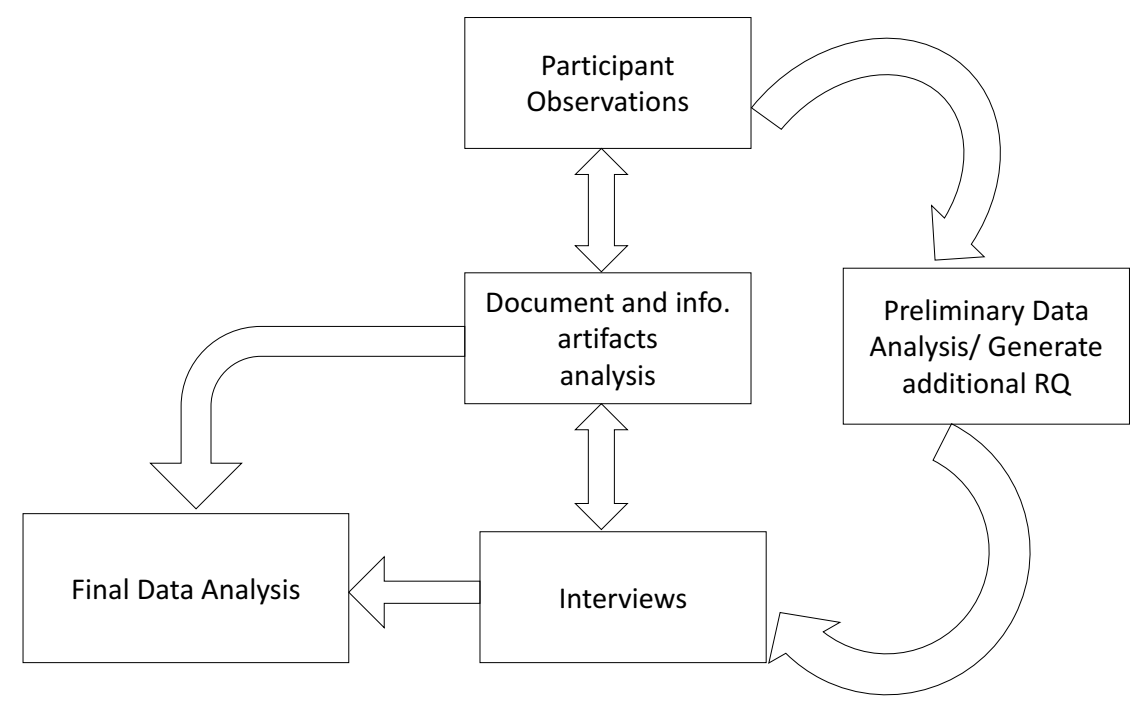

Figure 1. Data collection process

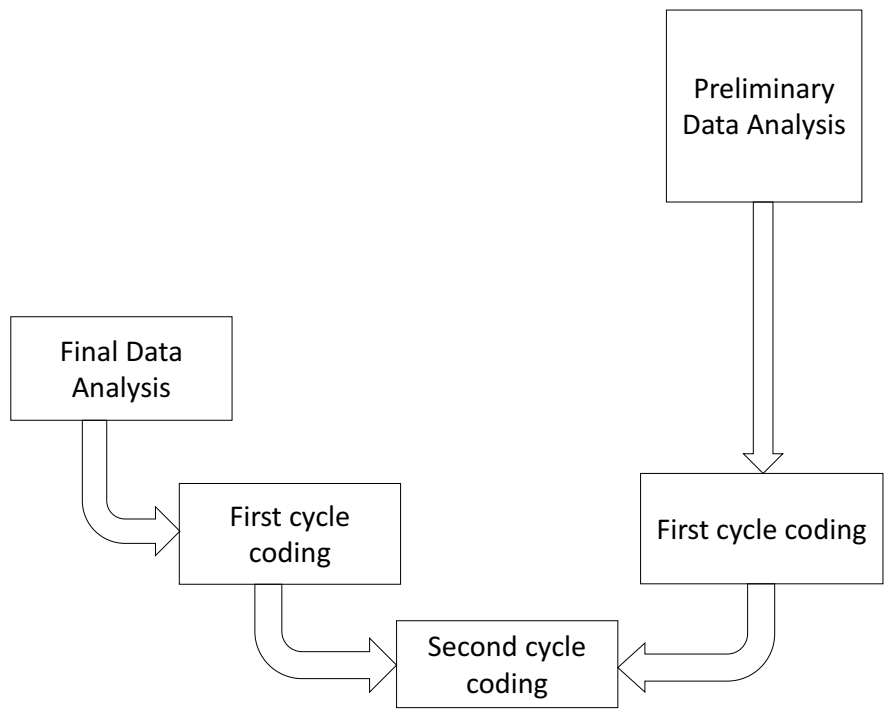

Figure 2. Data analysis process 


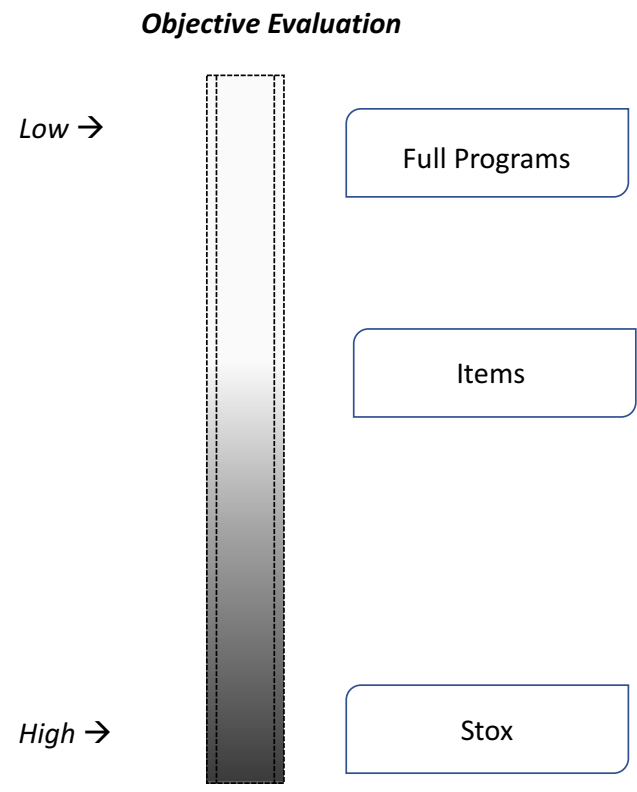

Subjective Evaluation

Figure 3. Subjectivity in evaluation in relation to type of materials

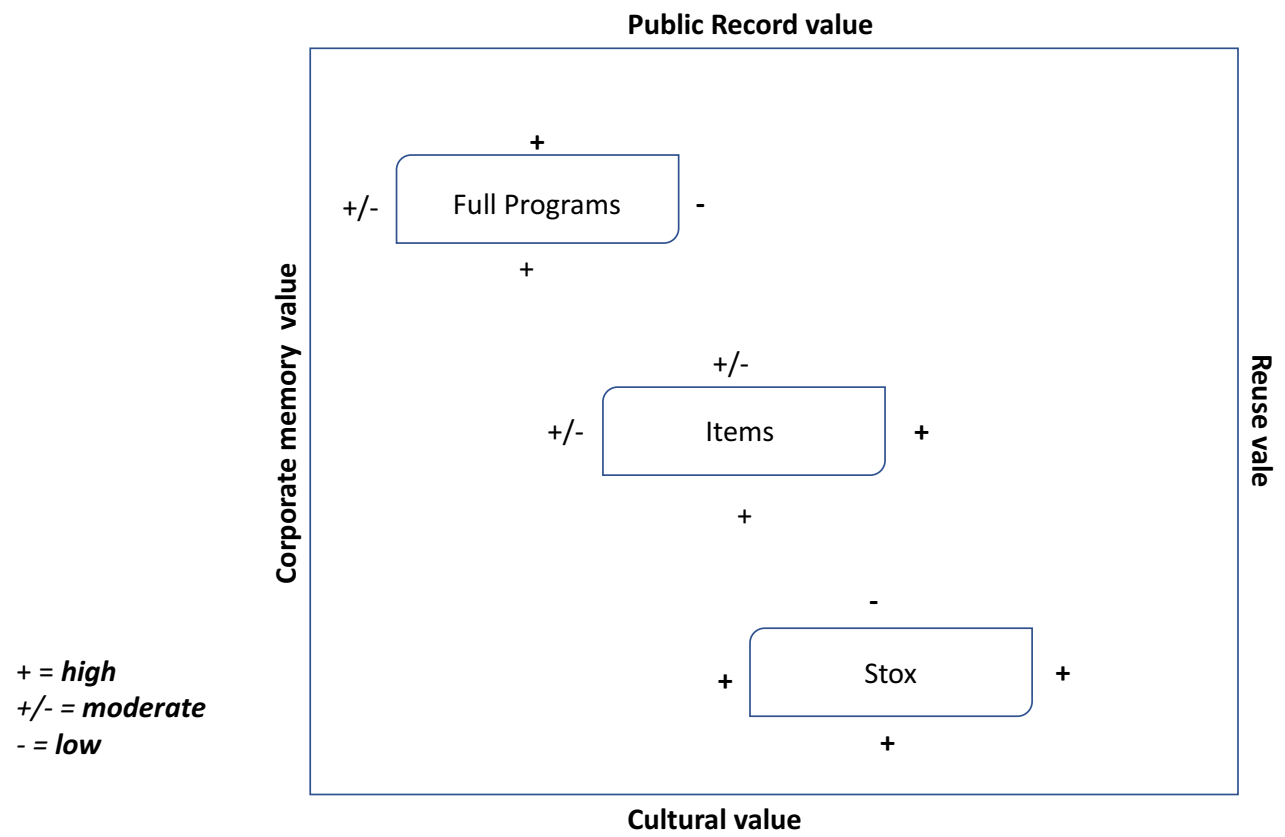

Figure 4 . Relation between evaluation logics and classes of archival materials 